\title{
A Method for Rockburst Prediction in the Deep Tunnels of Hydropower Stations Based on the Monitored Microseismicity and an Optimized Probabilistic Neural Network Model
}

\author{
Guangliang Feng ${ }^{1, *,+} \mathbb{D}$, Guoqing Xia ${ }^{2, *,+}$, Bingrui Chen ${ }^{1}$, Yaxun $X_{i a o}{ }^{1}$ and Ruichen Zhou ${ }^{3}$ \\ 1 State Key Laboratory of Geomechanics and Geotechnical Engineering, Institute of Rock and Soil Mechanics, \\ Chinese Academy of Sciences, Wuhan 430071, China; brchen@whrsm.ac.cn (B.C.); yxxiao@whrsm.ac.cn (Y.X.) \\ 2 School of Earth Sciences and Engineering, Nanjing University, Nanjing 210023, China \\ 3 Faculty of Engineering, China University of Geosciences (Wuhan), Wuhan 430074, China; \\ zrc_unique@outlook.com \\ * Correspondence: glfeng@whrsm.ac.cn (G.F.); x991038422@163.com (G.X.); Tel.: +86-19907130061 (G.F.) \\ + These authors contributed equally to this work.
}

Received: 29 March 2019; Accepted: 3 June 2019; Published: 10 June 2019

check for updates

\begin{abstract}
Hydropower is one of the most important renewable energy sources. However, the safe construction of hydropower stations is seriously affected by disasters like rockburst, which, in turn, restricts the sustainable development of hydropower energy. In this paper, a method for rockburst prediction in the deep tunnels of hydropower stations based on the use of real-time microseismic (MS) monitoring information and an optimized probabilistic neural network (PNN) model is proposed. The model consists of the mean impact value algorithm (MIVA), the modified firefly algorithm (MFA), and PNN (MIVA-MFA-PNN model). The MIVA is used to reduce the interference from redundant information in the multiple MS parameters in the input layer of the PNN. The MFA is used to optimize the parameter smoothing factor in the PNN and reduce the error caused by artificial determination. Three improvements are made in the MFA compared to the standard firefly algorithm. The proposed rockburst prediction method is tested by 93 rockburst cases with different intensities that occurred in parts of the deep diversion and drainage tunnels of the Jinping II hydropower station, China (with a maximum depth of $2525 \mathrm{~m}$ ). The results show that the rates of correct rockburst prediction of the test samples and learning samples are $100 \%$ and $86.75 \%$, respectively. However, when a common PNN model combined with monitored microseismicity is used, the related rates are only $80.0 \%$ and $61.45 \%$, respectively. The proposed method can provide a reference for rockburst prediction in MS monitored deep tunnels of hydropower projects.
\end{abstract}

Keywords: energy; rockburst prediction; microseismicity; probabilistic neural network; Jinping II hydropower station

\section{Introduction}

With the rapid growth of the global population and economic development worldwide, the need for clean energy sources is increasing. Energy security is undoubtedly one of the main building blocks of economic development and social and political stability [1]. Hydropower is one of the most important renewable energy sources. Of all renewable energy sources, hydropower produces the most energy, contributing $\sim 16 \%$ to global electricity production. Hydropower also has a positive effect on water supply, irrigation, flood control, and ice prevention, if properly handled [2]. According to statistics from the International Renewable Energy Agency, over the past decade, global installed hydropower has 
increased from $926,340 \mathrm{MW}$ to $1,245,708 \mathrm{MW}$, making a great contribution to energy transformation. It is expected that hydropower will continue to dominate more than half of the worldwide installed capacity of renewables in the future [3-5]. Therefore, an increasing number of hydropower stations have been constructed, such as the Jinping II, Xiluodu, Baihetan, Shimen, Jilebulake, Sinan River, and Pankou stations in China, and the Neelum-Jhelum station in Pakistan [2,4-8]. There are many deep tunnels in these hydropower projects. Many rockbursts occurred during the tunnel excavation due to high in situ stress at some of the hydropower stations. A rockburst is defined as damage to an excavation that occurs in a sudden or violent manner and is associated with a seismic event $[9,10]$. It is a type of dynamic disaster encountered in deep, hard rock underground engineering. With the expansion of the scale of deep underground engineering operations, rockbursts occur more frequently and with greater severity [8-21]. Two rockburst examples are shown in Figure 1. The safety of hydropower station construction is seriously affected by rockburst disaster, which restricts the sustainable development of hydropower energy. Therefore, how to predict rockburst so as to reduce casualties and equipment and economic losses during hydropower station construction urgently needs to be addressed.

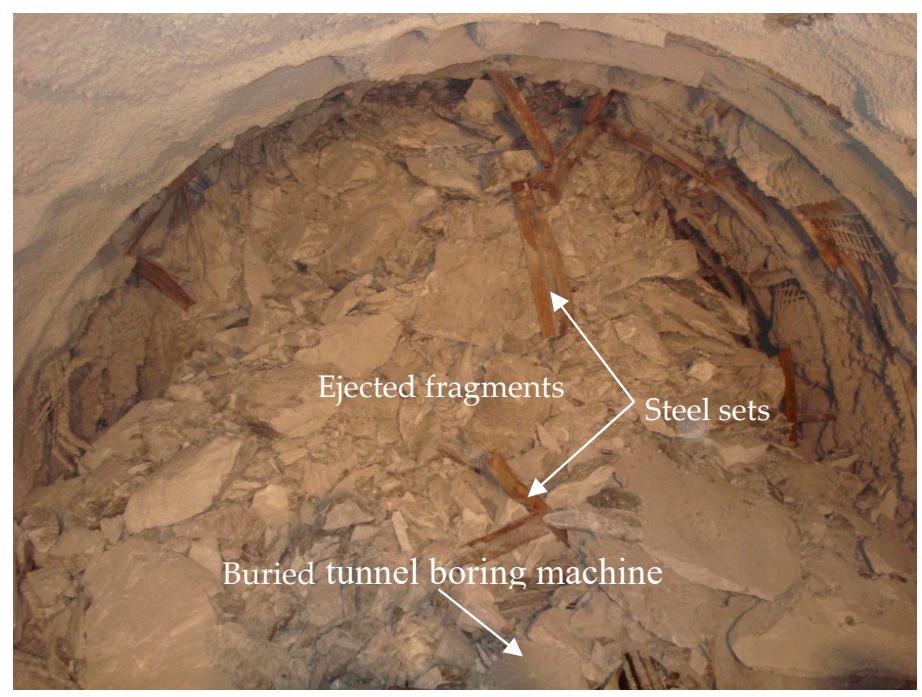

(a)

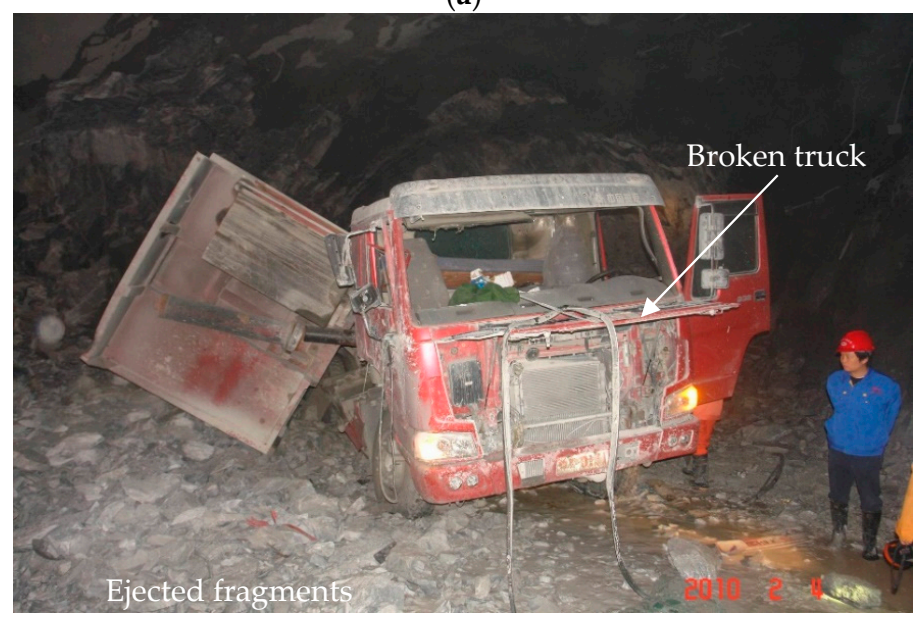

(b)

Figure 1. Examples of rockbursts in tunnels of the Jinping II hydropower station, China. (a) Extremely intense rockburst on 28 November 2009 in drainage tunnel that caused seven deaths and one injury and total destruction of a tunnel boring machine. (b) Extremely intense rockburst on 4 February 2010 in headrace tunnel \#2 that created three fissures in the floor. A truck was severely damaged and its windshield was shattered. Three workers in the truck were injured by the violent shakes [20]. 
Microseismic (MS) monitoring techniques involving the three-dimensional monitoring of MS events produced by the microcracking of rocks have been widely used around the world for many years to monitor and predict rockbursts, with different degrees of success [8,14-26]. For example, Feng et al. [14] proposed a dynamic method of warning of rockburst development processes in tunnels based on monitored microseismicity. The method has been successfully applied to rockburst warning in deep tunnels of the Jinping II hydropower project. Xu et al. [21] found that the MS source cluster of one extremely intense rockburst was the result of the combined effects of movement in the geological structure. The concentration of MS events before strainburst was found to be a significant precursor in a deep rock tunnel of the hydropower project. Liu et al. [22] studied the temporal and spatial variations in MS activities in an attempt to predict ground pressure hazards in the Hongtoushan copper mine in China. MS data contain enormous amounts of information; however, the problem of how to utilize the data to make accurate rockburst predictions remains to be solved.

Other researchers have suggested a combination of artificial intelligence and rock mechanics. For example, neural networks, fuzzy comprehensive evaluation methods, analytic hierarchy processes, random forest methods, Bayesian models, support vector machines, cloud models, multivariate time series reconstruction, abstraction ant colony clustering algorithms, etc. [8,27-34], have been used to study rock mechanics problems. Therefore, we can try to predict and can warn of rockburst risk by using the intelligent method and MS data together. Neural networks derived from modeling of the human brain can display good performance in signal restoration [33]. Feng et al. [8] used MS information and a neural network to predict rockburst risk in deep tunnels of the Jinping II hydropower project. Zhou et al. [34] successfully predicted the risk of rockburst in the construction of Tongyu and Qinling tunnels by using the probabilistic neural network (PNN) model; however, when using PNN for rockburst prediction, if the dimension of variables in input samples is large or there is a correlation between the variables, the prediction performance will be reduced [35], and the parameter smoothing factor in PNN affects the classification performance [36].

PNN is used for rockburst prediction in this paper. However, in order to reduce the correlation between MS parameters and determine the smoothing factor accurately in the PPN model used for rockburst prediction, an optimized PNN model is proposed. In this model, the mean impact value algorithm (MIVA) is used to reduce the dimension of the input index (monitored MS parameters) in the PNN, and a modified firefly algorithm (MFA) is used to optimize the parameter smoothing factor therein (MIVA-MFA-PNN model). Then, a rockburst prediction method in the deep tunnel of the hydropower station using real-time MS monitoring information and the optimized model is established. The prediction accuracy and applicability of the method are verified by 93 rockburst cases in the diversion and drainage tunnels of the Jinping II hydropower station, China (with a maximum depth of $2525 \mathrm{~m}$ ). The proposed method can provide a reference for rockburst prediction in MS monitored deep tunnels of hydropower projects.

\section{An Optimized PNN Model for Rockburst Prediction: MIVA-MFA-PNN}

The MIVA-MFA-PNN model proposed in this paper consists of MIVA, MFA, and PNN. The MIVA is used to reduce the interference from redundant information in the multiple MS parameters in the input layer of the PNN. The MFA is used to optimize the parameter smoothing factor in the PNN and reduce the error caused by artificial determination. There are three improvements in the MFA compared to the standard firefly algorithm.

\subsection{PNN Model}

The PNN is a type of adjusted radial basis function network and is a feed-forward neural network. It is a supervised network classifier based on Bayesian decision theory with the advantages of a simple learning process, high accuracy of pattern classification, strong fault tolerance, and generalizability [33]. The topological structure of the PNN is shown in Figure 2. 


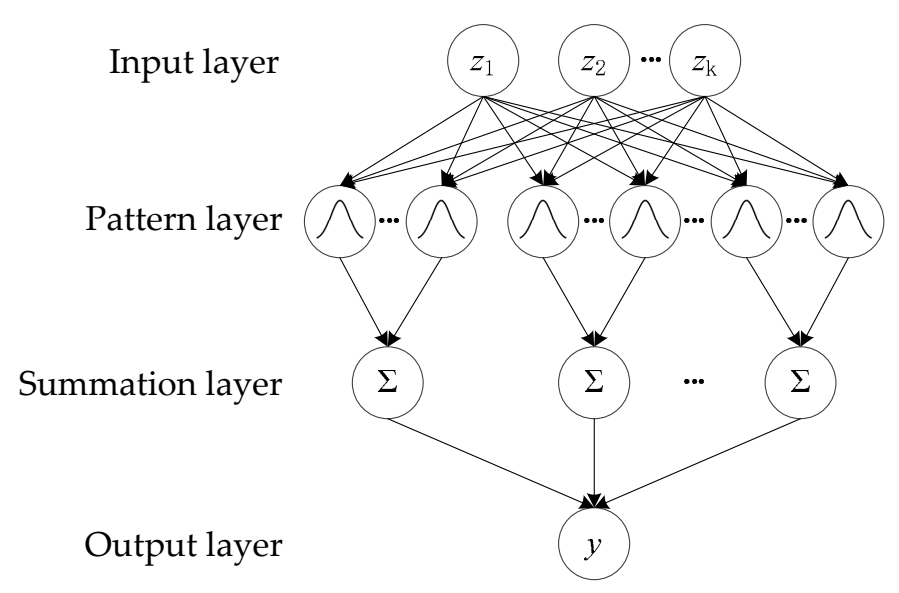

Figure 2. Probabilistic neural network (PNN) block diagram.

In Figure 2, the first layer is the input layer. The input vector is $X=\left(z_{1}, z_{2}, \ldots, z_{k}\right), k$ is the number of neurons, and $z_{k}$ is the $k$ th neuron. The second layer is the pattern layer. The output from the second layer is given by

$$
f\left(X, w_{k}\right)=\frac{1}{(2 \pi)^{p / 2} \sigma^{p}} \exp \left(-\frac{\left(x_{k}-w_{k}\right)^{T}\left(x_{k}-w_{k}\right)}{2 \sigma^{2}}\right)
$$

In Equation (1), $w_{k}$ is the weight of the neuron in the input layer, $p$ is the dimension of each sample, and $\sigma$ is the smoothing factor. The third layer is the summation layer, in which the output probability of the implicit neurons belonging to the same class in the pattern layer is accumulated. In the third layer, a weighted result is obtained by using Equation (2):

$$
v_{m}=\frac{\sum_{l=1}^{Q} f\left(X, w_{i}\right)_{l}}{Q}
$$

In Equation (2), $m$ denotes the number of classes to be identified and $v_{m}$ denotes the class output. $Q$ denotes the total number of neurons of class $m$ and $l$ is the $l$ th neuron in the pattern layer. The fourth layer is the output layer. The maximum median value in the summation layer is 1 and in the others is 0 . The class related to 1 in the summation layer is the class of the sample. As shown in Equation (3), $y$ is the output category:

$$
y=\operatorname{argmax}\left(v_{m}\right)
$$

\subsection{MIVA}

Duda et al. [37] found that when the dimension of the feature vector exceeds the threshold, the accuracy of the classifier will decrease, and if the eigenvectors are mutually correlated, the performance of the classifier decreases. If the dimension of the parameter in the MS information is large, and there are multiple collinearities among the parameters, the prediction result of rockburst by the PNN will be poor. Therefore, the MIVA is used to reduce the dimension of each parameter, thus solving the problem of data redundancy in input samples.

The MIVA, which was proposed by Dombi et al. [38], is a single factor sensitivity analysis method. The specific calculation method is as follows; data pertaining to one parameter in the original training sample $I$ varies by $\pm 10 \%$ (which can be adjusted) and the other parameter values remain unchanged. New input samples $\left(I_{1}\right.$ and $\left.I_{2}\right)$ are then obtained. After inputting the new input samples in the trained neural network model, we can get the outputs $O_{1}$ and $O_{2}$. The difference between $O_{1}$ and $O_{2}$ is the impact value (IV), which comes from the change in the independent variable. After dividing the IV by the total number of samples, we can get the effect of the parameter fluctuations on the output of the 
neural network; this is, in essence, the MIV. The same operation is performed on each parameter in the input sample to get the MIV for each parameter; the MIV of each parameter can be taken as the rate of contribution to the output result, and parameters with strong correlations can be combined into a new parameter according to the proportion of contributions. This can reduce the dimension of the input sample and the linear correlation among the parameters.

\subsection{MFA}

An improved firefly algorithm is used to determine the smoothing factor in this PNN. The firefly algorithm [39] is a swarm intelligence optimization algorithm based on the luminescence of fireflies and their mutually attractive group behavior. It has been successfully applied to solve optimization problems in many fields [40,41]. It offers the advantages of simplicity and few required parameters and has better performance than a genetic algorithm or particle swarm optimization algorithm in optimizing some test functions.

Assuming that the solution space of the objective function to be optimized is $d$-dimensional, a group of fireflies $\left(x_{1}, x_{2}, \ldots, x_{n}\right)$ is initialized randomly, where $n$ is the number of fireflies and $\left(x_{i 1}, x_{i 2}, \ldots, x_{i d}\right)^{T}$ represents a possible solution of the objective function to be optimized, denoting the position of firefly $x_{i}$ in the solution space. The absolute brightness of firefly $i$ is recorded as $I_{i}$, and its value is equal to that of the objective function of firefly $x_{i}$, that is,

$$
I_{i}=f\left(x_{i}\right)
$$

The relative brightness of firefly $i$ to firefly $j$ is recorded as $I_{i j}$, with a value of

$$
I_{i j}=I_{i} e^{-\gamma r_{i j}}
$$

where $\gamma$ is the light absorption coefficient within the range $[0.01,100]$ and $r_{i j}$ is the Euclidean distance from firefly $i$ to firefly $j$.

The attractive force $\beta_{i j}$ of firefly $i$ to firefly $j$ is given by

$$
\beta_{i j}=\beta_{0} e^{-\gamma r_{i j}^{2}}
$$

where $\beta_{0}$ is the largest attraction force of fireflies in the light source (generally $\beta_{0}=1$ ). A firefly is attracted to another firefly with greater brightness. The location updating formula is as follows

$$
x_{j}(t+1)=x_{j}(t)+\beta_{i j}\left(x_{i}(t)-x_{j}(t)\right)+\alpha \varepsilon
$$

In Equation (7), $t$ is the number of iterations; $x_{i}$ and $x_{j}$ are the spatial positions of fireflies $i$ and $j$; and $\alpha \varepsilon$ is a random disturbance term, where $\alpha$ is generally a constant within [0,1]; and $\varepsilon$ is a uniformly distributed random number vector. By updating the position and brightness, fireflies will gather around other fireflies with higher brightness, and the optimal solution of the objective function can be obtained.

The standard firefly algorithm tends to find a local optimum solution, and the phenomenon of "precocity" arises, which leads to poor global search ability. Convergence of the algorithm is slow when a large-range function is optimized. Therefore, considering the properties of smoothing factors in the PNN, the following three improvements are used to improve the ability of the standard firefly algorithm.

(1) Optimization of the initial positions of fireflies

When the smoothing factor of the PNN is optimized by the standard firefly algorithm, the position of the firefly represents the value of the smoothing factor. In the standard firefly algorithm, the initial position of the firefly is determined randomly. Considering that the value range of the smoothing factor is generally $(0,1]$, to reduce the search range and convergence time and improve the global 
search ability of fireflies, the initial positions of fireflies are uniformly distributed on $(0,1]$. The initial position of the firefly is given by

$$
x_{i}=\frac{i}{q}
$$

where $q$ is the number of fireflies.

(2) Improvement of the perturbed term in the position updating formula

If the random perturbation term in the position updating formula has a large step size in the early iterations of the algorithm, the fireflies can search for the optimal solution in the global range. If the step size decreases gradually in later iterations of the algorithm, a firefly can fine search in a local area. In order to obtain the performance above, $\alpha \varepsilon$ in Equation (7) is optimized as follows

$$
\alpha \varepsilon=\left(1-\frac{t}{\text { MaxGegeration }}\right)(2 \text { rand }-1) r_{\mathrm{ij}}
$$

where MaxGeneration is the maximum number of iterations, $t$ is the number of the current iteration, and rand is a random number of uniform distribution on [0,1]. When the distance between fireflies is large, the second term (attractive force) in the position updating Equation (7) is affected slightly on the renewal of a firefly's position. At this point, the random perturbation term makes the firefly move autonomously within $\left[-r_{i j}, r_{i j}\right]$. Therefore, the algorithm can search in a larger space. (1-t/MaxGeneration) is the number of random perturbation terms, which decreases with the iteration. Therefore, the MFA has better global search ability in the early stage of iteration and better local search ability in the later stage.

(3) Improvement of the attractive force formula

From Equation (6), it can be found that when the distance $r_{i j}$ between fireflies tends to be positive infinity, that is, when the distance is big enough, the attractive force $\beta_{i j}$ tends to be zero. This is not good for the renewal of its position. In order to solve this problem, the minimum attraction $\beta_{\min }$ is proposed and used. $\beta_{\min }$ guarantees that even if the distance between fireflies is large, there is still a certain attractive force to make the positions of fireflies update normally. The improved formula for attractive force is given by

$$
\beta_{i j}=\left(\beta_{0}-\beta_{\min }\right) e^{-\gamma r_{i j}{ }^{2}}+\beta_{\min }
$$

The error rate of the predicted results of test samples based on the PNN is regarded as the objective function in the MFA. Then the smoothing factor in the PNN model can be obtained and optimized by searching the minimum error rate in the solution space. This will reduce the error caused by determining the smoothing factor based on the trial method in the PNN model. The pseudocode of the smoothing factor search in the PNN model is shown in the Appendix A.

To sum up, in the proposed MIVA-MFA-PNN model, the MIVA is used to reduce the dimension of the original evaluation index in the PNN. This will reduce interference from redundant information in the sample, and the input layer neuron in the PNN and complexity of the PNN structure are both reduced. Considering the properties of the smoothing factor in the PNN, three improvements are made in the standard firefly algorithm and the MFA is proposed. It will improve the global search ability and the rate of convergence. The error caused by empirical determination of the smoothing factor will be avoided. Therefore, when the new model is combined with the real-time monitored MS information, a good prediction result of rockburst in the tunnel of the hydropower project can be obtained.

The process of rockburst prediction based on the monitored MS information and the proposed MIVA-MFA-PNN model is as follows; first, a correlation analysis of the MS parameters is carried out. If the correlation among parameters is strong, the mean influence value of each parameter will be calculated by using the MIVA. The parameters with strong correlation will be combined with each other to form a new evaluation index for rockburst prediction. Second, the smoothing factor in the PNN is optimized by the MFA to reduce the error caused by experience determination. Finally, the data pertaining to the new evaluation index are used as the input sample of the MIVA-MFA-PNN model to output the rockburst prediction result. 
3. Application of the Rockburst Prediction Method to Deep Tunnels of Hydropower Stations: A Case Study

\subsection{Engineering Overview}

The deep tunnels of the Jinping-II hydropower project (located on the Yalong River, Sichuan Province, Southwest China) are illustrated in Figure 3. It has a total installed capacity of $4800 \mathrm{MW}$, which provides an average annual generation of $24.23 \mathrm{TWh}$. The station relies on the water flowing along a $150 \mathrm{~km}$ reach of the Yalong River and uses a $310 \mathrm{~m}$ natural fall to generate power. This station has the highest waterhead $(288 \mathrm{~m})$ and the largest installed capacity of stations along the river. Seven main tunnels were excavated: four are diversion tunnels (\#1-4) and two are auxiliary tunnels (A and B). Between the diversion and auxiliary tunnels, there is a drainage tunnel that is used to discharge excess water. The eastern ends of the tunnels are mainly buried in the $T_{2 y}$ marble of the Yantang group, whereas the western ends are in the $T_{1}$ chlorite schist, $T_{3}$ sand slate, and $T_{2 z}$ marble of the Zagunao group and the middle of the $T_{2 b}$ marble of the Baishan group. Approximately $80 \%$ of the rock mass the tunnels pass through is of marble lithology. The strata that the headrace tunnels pass through are all Triassic: lower Triassic $\left(T_{1}\right)$, salt tang group $\left(T_{2 y}\right)$, Baishan group $\left(T_{2 b}\right)$, miscellaneous valley brain group $\left(T_{2 z}\right)$, and upper Triassic $\left(T_{3}\right)$. The sections of the headrace tunnels are mainly composed of moderately thick $T^{5}{ }_{2 y}$ marble, thin-layered $T^{6}{ }_{2 y}$ marble, and a thick layer of $T_{2 b}$ marble. The $T^{5}{ }_{2 y}$ and $T_{2 b}$ strata have typical features of high-strength compact rock structures, and the strainburst hazard is high when tunneling through these strata. More than $75 \%$ of the tunnel sections have an overburden depth greater than $1700 \mathrm{~m}$. Most of the tunnel's rock consists of marble, which is characterized by its brittleness and high strength (uniaxial compressive strength is $\sim 100 \mathrm{MPa}$ and tensile strength is 3-6 MPa). Rockbursts with different intensities occurred frequently in the construction of the tunnels. MS monitoring was conducted in some of the tunnels [18]; MS monitoring and microseismicity data analysis have been described in detail elsewhere [5,9,18-22].

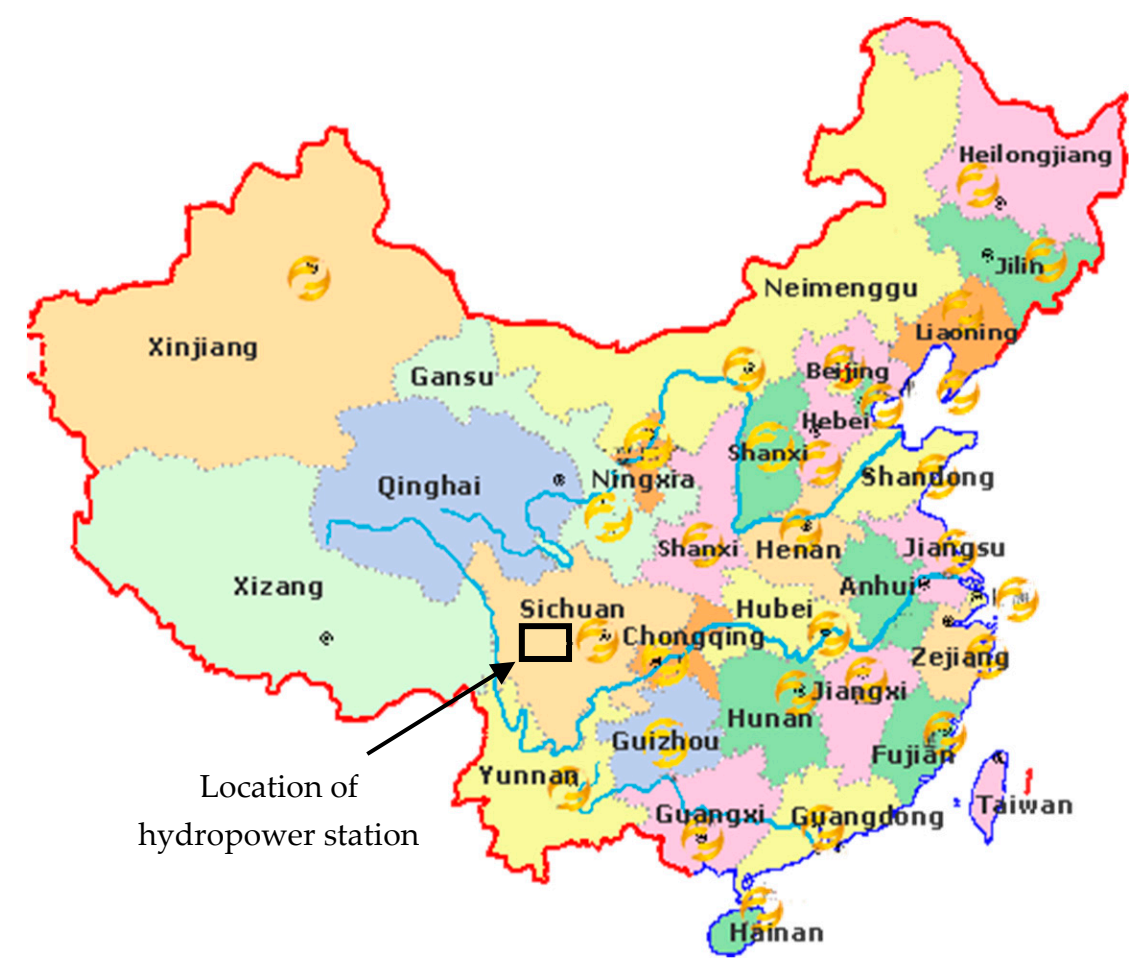

(a)

Figure 3. Cont. 


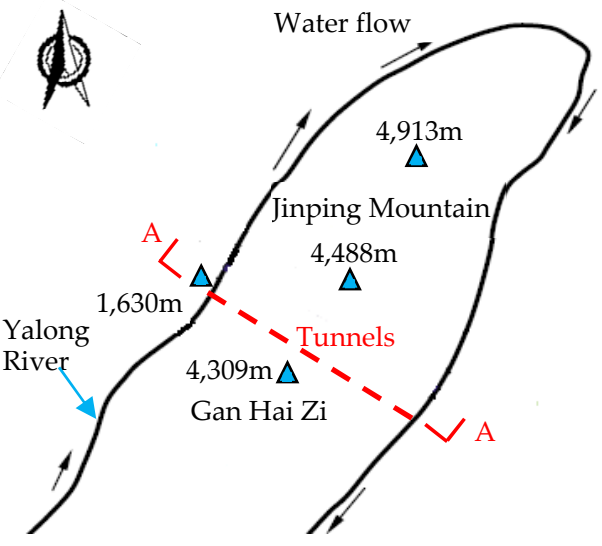

(b)

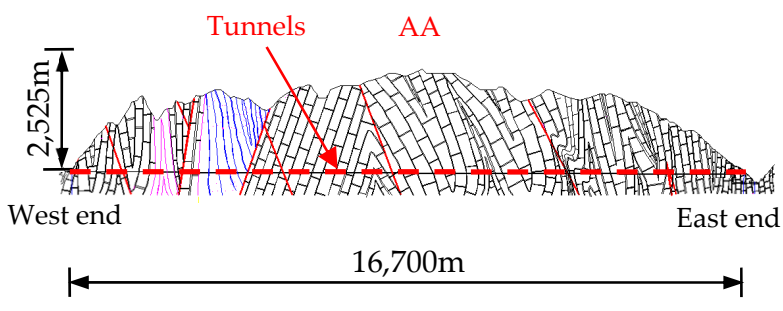

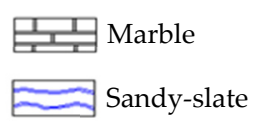

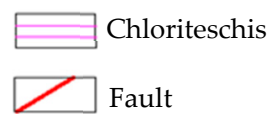

(c)

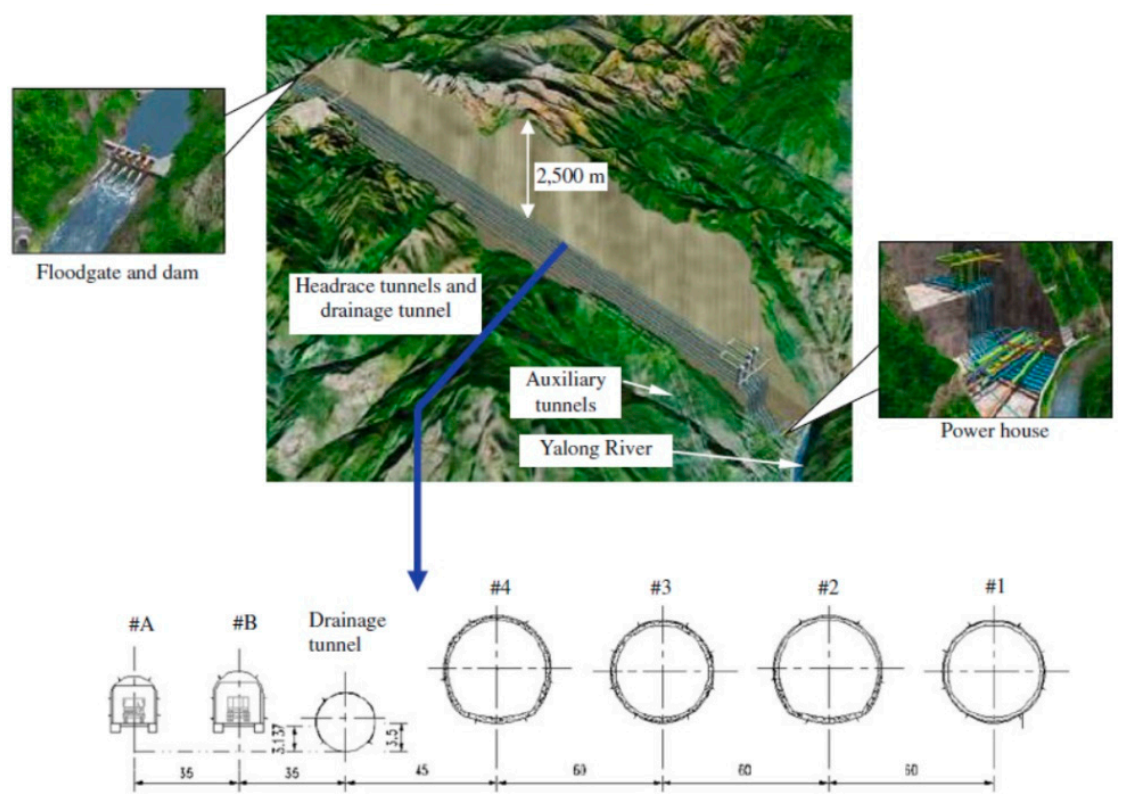

(d)

Figure 3. Deep tunnels of Jinping II hydropower station, China. (a) Map of China and location of the station, (b) plan of the station, (c) geological cross-section along the tunnels, and (d) layout of the tunnels [19].

\subsection{Input and Output Layers in the MIVA-MFA-PNN Rockburst Prediction Model}

The input layer is the real-time MS monitoring information in the deep tunnels of the Jinping II hydropower project. Considering that the selected evaluation index should be closely related to microfracture activity in the rockburst development process and can reflect the evolution of the rockburst, six MS parameters reflecting the accumulation of total rupture time, strength, and deformation of the rock mass are selected. Originally, the cumulative number of MS events $(N)$, cumulative MS energy $(E)$, and cumulative MS apparent volume $(V)$ were considered for rockburst prediction in the drilling and blasting tunnel. To account for the temporal evolution factor, three MS parameters pertaining to time were added: event rate $(n)$, energy rate $(e)$, and apparent volume rate $(v)$.

The output layer is the rockburst intensity. Because there is no extreme rockburst in the collected rockburst cases, the output rockburst intensities are intense, moderate, slight, and no rockburst. Considering that the output of a PNN is 0 or 1 , the output data are set as follows; $[1,0,0,0],[0,1,0,0]$, $[0,0,1,0]$, and $[0,0,1,0]$, representing intense, moderate, slight, and no rockburst, respectively. 


\subsection{Samples}

Some 93 events in part of the diversion and drainage tunnels were used as samples (13 intense, 25 moderate, and 21 slight rockbursts, and 34 nonevents). The number of rockbursts with different intensities approximately obeys a Gaussian distribution. A total of 10 cases were selected from the 93 cases as test samples. The remaining 83 cases were used as learning samples to verify the prediction result. Some cases are listed in Table 1 as examples. The values of the six MS parameters and the rockburst intensity of the cases are shown in Table 1, where IV, III, II, and I represent intense, moderate, slight, and no rockburst, respectively.

Table 1. Learning and testing samples.

\begin{tabular}{|c|c|c|c|c|c|c|c|c|c|c|c|}
\hline \multirow{2}{*}{$\begin{array}{l}\text { Sample } \\
\text { Category }\end{array}$} & \multirow{2}{*}{ No. } & \multicolumn{6}{|c|}{ MS Monitoring Information } & \multicolumn{4}{|c|}{ Rockburst Intensity } \\
\hline & & $N$ & $\operatorname{Lg}(E / \mathrm{J})$ & $\operatorname{Lg}\left(V / \mathrm{m}^{3}\right)$ & $n(1 / \mathrm{d})$ & $\operatorname{Lg}(e / \mathrm{J} / \mathrm{d})$ & $\operatorname{Lg}\left(v / \mathrm{m}^{3} / \mathrm{d}\right)$ & IV & III & II & I \\
\hline \multirow{24}{*}{$\begin{array}{l}\text { Learning } \\
\text { sample }\end{array}$} & 1 & 45 & 4.803 & 4.838 & 4.091 & 3.762 & 3.796 & 1 & 0 & 0 & 0 \\
\hline & 2 & 11 & 4.110 & 3.624 & 2.200 & 3.411 & 2.925 & 1 & 0 & 0 & 0 \\
\hline & 3 & 49 & 6.419 & 4.995 & 12.250 & 5.817 & 4.393 & 1 & 0 & 0 & 0 \\
\hline & 4 & 29 & 5.513 & 4.777 & 5.800 & 4.814 & 4.078 & 1 & 0 & 0 & 0 \\
\hline & 5 & 70 & 6.147 & 5.152 & 7.000 & 5.147 & 4.152 & 1 & 0 & 0 & 0 \\
\hline & 6 & 58 & 7.094 & 4.975 & 3.625 & 5.890 & 3.771 & 1 & 0 & 0 & 0 \\
\hline & 18 & 17 & 4.754 & 4.397 & 1.889 & 3.800 & 3.443 & 0 & 1 & 0 & 0 \\
\hline & 19 & 6 & 5.008 & 4.627 & 1.148 & 3.577 & 3.195 & 0 & 1 & 0 & 0 \\
\hline & 20 & 11 & 4.966 & 4.154 & 2.750 & 4.364 & 3.552 & 0 & 1 & 0 & 0 \\
\hline & 21 & 18 & 5.295 & 4.703 & 1.800 & 4.295 & 3.703 & 0 & 1 & 0 & 0 \\
\hline & 22 & 10 & 5.322 & 4.238 & 1.429 & 4.477 & 3.393 & 0 & 1 & 0 & 0 \\
\hline & 23 & 3 & 5.060 & 4.438 & 0.429 & 4.215 & 3.593 & 0 & 1 & 0 & 0 \\
\hline & 43 & 10 & 4.614 & 4.611 & 1.111 & 3.660 & 3.657 & 0 & 0 & 1 & 0 \\
\hline & 44 & 29 & 3.882 & 4.156 & 2.900 & 2.882 & 3.156 & 0 & 0 & 1 & 0 \\
\hline & 45 & 20 & 4.760 & 3.843 & 1.250 & 3.556 & 2.639 & 0 & 0 & 1 & 0 \\
\hline & 46 & 4 & 4.530 & 4.557 & 0.667 & 3.752 & 3.779 & 0 & 0 & 1 & 0 \\
\hline & 47 & 12 & 3.543 & 4.223 & 4.000 & 3.066 & 3.746 & 0 & 0 & 1 & 0 \\
\hline & 48 & 3 & 4.610 & 3.732 & 1.000 & 4.133 & 3.255 & 0 & 0 & 1 & 0 \\
\hline & 66 & 7 & 4.300 & 3.018 & 0.778 & 3.345 & 2.064 & 0 & 0 & 0 & 1 \\
\hline & 67 & 1 & 2.970 & 4.164 & 0.333 & 2.493 & 3.687 & 0 & 0 & 0 & 1 \\
\hline & 68 & 5 & 3.996 & 3.279 & 1.000 & 3.297 & 2.58 & 0 & 0 & 0 & 1 \\
\hline & 69 & 2 & 1.210 & 4.146 & 0.500 & 0.608 & 3.544 & 0 & 0 & 0 & 1 \\
\hline & 70 & 5 & 3.154 & 3.309 & 2.500 & 2.853 & 3.008 & 0 & 0 & 0 & 1 \\
\hline & 71 & 4 & 5.820 & 3.728 & 0.308 & 4.706 & 2.614 & 0 & 0 & 0 & 1 \\
\hline \multirow{10}{*}{$\begin{array}{c}\text { Test } \\
\text { sample }\end{array}$} & 7 & 41 & 5.968 & 4.694 & 3.727 & 4.926 & 3.653 & 1 & 0 & 0 & 0 \\
\hline & 13 & 44 & 5.459 & 4.865 & 2.933 & 4.283 & 3.689 & 1 & 0 & 0 & 0 \\
\hline & 17 & 20 & 5.982 & 4.453 & 2.500 & 5.079 & 3.550 & 0 & 1 & 0 & 0 \\
\hline & 27 & 23 & 4.408 & 4.873 & 2.556 & 3.454 & 3.918 & 0 & 1 & 0 & 0 \\
\hline & 35 & 12 & 5.098 & 3.516 & 1.714 & 4.253 & 2.671 & 0 & 1 & 0 & 0 \\
\hline & 42 & 7 & 4.834 & 4.116 & 0.538 & 3.721 & 3.002 & 0 & 0 & 1 & 0 \\
\hline & 51 & 6 & 5.561 & 4.043 & 1.000 & 4.783 & 3.265 & 0 & 0 & 1 & 0 \\
\hline & 65 & 3 & 3.668 & 3.609 & 0.500 & 2.890 & 2.831 & 0 & 0 & 0 & 1 \\
\hline & 76 & 4 & 4.737 & 4.173 & 0.800 & 4.038 & 3.374 & 0 & 0 & 0 & 1 \\
\hline & 82 & 5 & 2.435 & 3.878 & 0.455 & 1.393 & 2.836 & 0 & 0 & 0 & 1 \\
\hline
\end{tabular}

\subsection{Rockburst Intensity Prediction}

\subsubsection{MIVA Processing of Input Data}

It is necessary to reduce the dimension of the evaluation indices in the input when the correlation among some evaluation indices is strong. The correlation between input variables can be measured by the correlation coefficient $r$ (Table 2) [42]. Correlation analysis of the evaluation indices was conducted, and the result is shown in Table 3.

Table 3 shows a strong correlation among some evaluation indices. For example, the correlation between the cumulative number of MS events and the MS event rate is 0.788 (a strong positive correlation). The correlation between the cumulative MS apparent volume and the MS apparent 
volume rate is 0.888 . The correlation between the cumulative MS release energy and the MS energy rate is 0.974 . Therefore, dimensionality reduction of the six evaluation indices used as input should be carried out. In order to eliminate the large difference caused by different dimensions of the parameters in MS monitoring information, regularization transformation was conducted to normalize all the data (Equation (11)):

$$
x_{a b}^{*}=\frac{x_{a b}-x_{\min }}{x_{\max }-x_{\min }}
$$

where $a$ is the dimension of input data $(a=1,2, \ldots, 6), b$ is the total number of samples $(b=1,2, \ldots, 93)$, $x_{a b}$ represents the value of the MS parameter before normalization, $x_{a b}^{*}$ represents the normalized value of the MS parameter, and $x_{\max }$ represents the largest and $x_{\min }$ the smallest values of the MS parameter. After the transformation, the range of values of the sample data is $[0,1]$.

Table 2. Relationship between the size of $|\mathrm{r}|$ and the degree of relevance.

\begin{tabular}{cccccccc}
\hline Range of Values of $|\mathbf{r}|$ & $\mathbf{0}$ & $\mathbf{( 0 , 0 . 2 ]}$ & $\mathbf{( 0 . 2 , 0 . 4 ]}$ & $\mathbf{( 0 . 4 , 0 . 6 ]}$ & $\mathbf{( 0 . 6 , 0 . 8}]$ & $\mathbf{( 0 . 8 , 1 )}$ & $\mathbf{1}$ \\
\hline Degree of relevance & Irrelevance & Very weak & Weak & Medium & Strong & Extremely strong & Relevance \\
\hline
\end{tabular}

Table 3. Correlation of evaluation indices.

\begin{tabular}{ccccccc}
\hline Evaluation Index & $\boldsymbol{N}$ & $\operatorname{Lg} E$ & $\operatorname{Lg} V$ & $\boldsymbol{n}$ & $\operatorname{Lg} \boldsymbol{e}$ & $\operatorname{Lg} \boldsymbol{v}$ \\
\hline$N$ & 1 & - & - & - & - & - \\
$\operatorname{Lg} E$ & 0.524 & 1 & - & - & - & - \\
$\operatorname{Lg} V$ & 0.543 & 0.576 & 1 & - & - & - \\
$n$ & 0.788 & 0.408 & 0.385 & 1 & - & - \\
$\operatorname{Lg} e$ & 0.467 & 0.974 & 0.519 & 0.449 & 1 & - \\
$\operatorname{Lg} v$ & 0.415 & 0.400 & 0.888 & 0.453 & 0.439 & 1 \\
\hline
\end{tabular}

After the value of each evaluation index with transformation in the total sample was changed by $\pm 30 \%$, it was put into the PNN. The actual prediction results were obtained and were compared with the expected prediction results. The related change rates between the actual and expected prediction results are the MIVs, shown in Table 4. We find that some MIVs are large. For example, the MIV of the cumulative MS event number $N$ is 0.2796 , which indicates that the fluctuation of $N$ has a big influence on the output prediction result.

Table 4. Mean impact values (MIVs) of the six evaluation indices.

\begin{tabular}{ccccccc}
\hline Evaluation Index & $\boldsymbol{N}$ & $\operatorname{Lg} E$ & $\operatorname{Lg} V$ & $\boldsymbol{n}$ & $\operatorname{Lg} \boldsymbol{e}$ & $\operatorname{Lg} \boldsymbol{v}$ \\
\hline MIV & 0.2796 & 0.0430 & 0.0215 & 0.0108 & 0.0323 & 0.0108 \\
\hline
\end{tabular}

Form the results of Table $4, N$ and $n, \operatorname{Lg} E$ and $\operatorname{Lg} e$, and $\operatorname{Lg} V$ and $\operatorname{Lg} v$ are synthesized to form new parameters based on their MIVs, as shown in Equation (12). Then, new samples based on the new parameters can be obtained:

$$
\left\{\begin{array}{l}
P_{N}=\frac{M I V_{N}}{M I V_{N}+M I V_{n}} \times N+\frac{M I V_{n}}{M I V_{N}+M I V_{n}} \times n \\
P_{E}=\frac{M I V_{L g E}}{M I V_{L g E}+M I V_{L g e}} \times L g E+\frac{M I V_{L g e}}{M I V_{L g E}+M I V_{L g e}} \times L g e \\
P_{V}=\frac{M I V_{L g V}}{M I V_{L g V}+M I V_{L g v}} \times L g V+\frac{M I V_{L g v}}{M I V_{L g V}+M I V_{L g v}} \times L g v
\end{array}\right.
$$

where $P_{N}, P_{E}$, and $P_{V}$ are the new parameters used for rockburst prediction and $M I V_{N}, M I V_{n}$, $M I V_{L g E}, M I V_{L g e}, M I V_{L g V}$, and $M I V_{L g v}$ are the MIVs of the evaluation indices $N, L g E, L g V, n, L g e$, and $L g v$, respectively. 


\subsubsection{Determination of Smoothing Factor Based on the MFA}

The parameters in the MFA are set as follows; number of fireflies $n=20$, maximum number of iterations MaxGeneration $=50$, maximum attractive force $\beta_{0}=1$, minimum attractive force $\beta_{\min }=0.2$, and optical absorption coefficient $r=1$. The data after dimension reduction are used as input in the PNN. The results based on the PNN optimized with the MFA and with the firefly algorithm are shown in Figure 4.

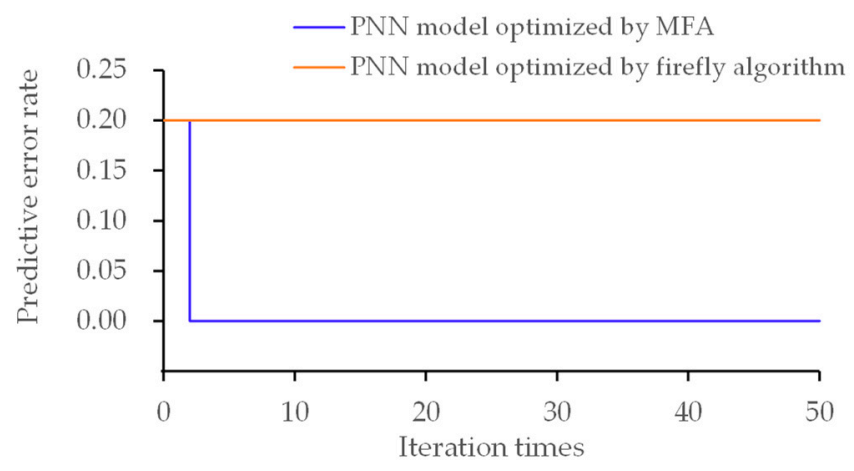

Figure 4. Result of predictive error rates by using PNN with modified firefly algorithm (MFA) and firefly algorithm.

From Figure 4, we find that when the firefly algorithm is used to optimize the smoothing factor in the PNN, it falls into a local optimum. The error rate in rockburst prediction in test samples stayed at the locally optimal result of 0.2 . However, by using the MFA, it reached a global optimum at the third iteration. This shows that convergence speed and global search ability are improved by the MFA. By using the MFA, the smoothing factor in the PNN is optimized, with a value of 0.0143 .

\subsubsection{Rockburst Prediction}

Results of rockburst prediction of the 10 test samples based on the MS monitoring information and the MIVA-MFA-PNN model are shown in Table 5. In Table 5, the expected output is the actual intensity of the rockburst and the actual output is the prediction result. The rockburst intensity predicted by the MIVA-MFA-PNN model is exactly the same as the actual results in the study sample. All 10 cases of test samples are predicted correctly. The error rate of rockburst prediction based on real-time MS monitoring information and the MIVA-MFA-PNN model is zero.

Table 5. Result of rockburst prediction based on MS monitoring information and the proposed optimized probabilistic neural network model.

\begin{tabular}{ccccccccc}
\hline \multirow{2}{*}{ No. } & \multicolumn{3}{c}{ Expected Output } & \multicolumn{4}{c}{ Actual Output } \\
\cline { 2 - 9 } & IV & III & II & I & IV & III & II & I \\
\hline 7 & 1 & 0 & 0 & 0 & 1 & 0 & 0 & 0 \\
13 & 1 & 0 & 0 & 0 & 1 & 0 & 0 & 0 \\
17 & 0 & 1 & 0 & 0 & 0 & 1 & 0 & 0 \\
27 & 0 & 1 & 0 & 0 & 0 & 1 & 0 & 0 \\
35 & 0 & 1 & 0 & 0 & 0 & 1 & 0 & 0 \\
42 & 0 & 0 & 1 & 0 & 0 & 0 & 1 & 0 \\
51 & 0 & 0 & 1 & 0 & 0 & 0 & 1 & 0 \\
65 & 0 & 0 & 0 & 1 & 0 & 0 & 0 & 1 \\
76 & 0 & 0 & 0 & 1 & 0 & 0 & 0 & 1 \\
82 & 0 & 0 & 0 & 1 & 0 & 0 & 0 & 1 \\
\hline
\end{tabular}

A comparison of predictions based on non-preprocessed original data and the PNN model with a smoothing factor of 0.1 was studied, and the result is shown in Figure 5. 


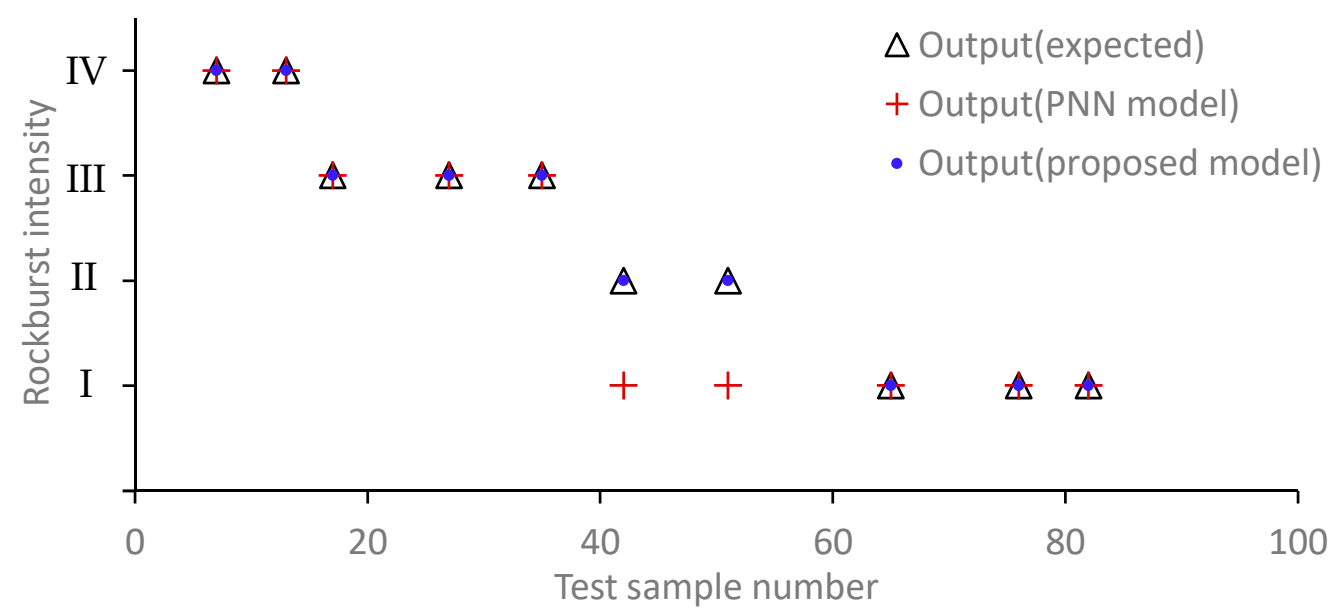

Figure 5. Comparison of prediction results between PNN and MIVA-MFA-PNN models.

It can be seen from Table 5 and Figure 5 that the MIVA-MFA-PNN model performs better for rockburst prediction than the PNN model. The rockburst predictions for the test samples using the MIVA-MFA-PNN model are all correct, while only $80 \%$ are correct using the PNN model. Two samples (42 and 51) were originally moderate rockbursts but were wrongly predicted as nonevents.

The results of rockburst prediction of the learning samples based on the MIVA-MFA-PNN model are shown in Figure 6. There are 11 rockburst cases with incorrect predictions (correct prediction rate of $86.75 \%$ ). The learning samples with incorrect predictions are summarized in Table 6 . The reasons for the few incorrect predictions are as follows; (1) in some samples, there is a large dispersion of MS parameter values. For example, microseismicity of rockburst case 2 greatly differs from the statistical characteristics of rockbursts of that intensity. (2) In order to ensure good generalizability, the neural network tries to avoid overfitting. In this case, the best generalization error is achieved by sacrificing the training error. (3) The number of samples is not large enough. In this case, the characteristics of the rockburst cannot be learned very well by the MIVA-MFA-PNN model.

When the common PNN model is used to predict the rockburst of the learning samples, the correct rate is only $61.45 \%$. Once again, the proposed MIVA-MFA-PNN model is better for rockburst prediction.

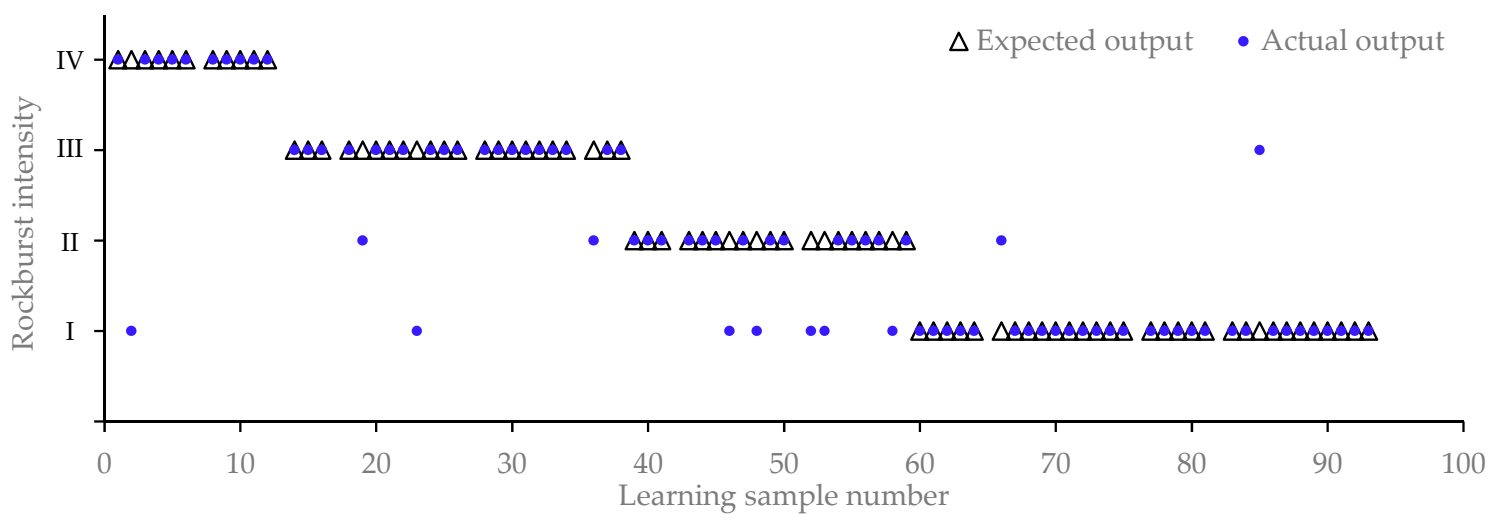

Figure 6. Result of rockburst prediction with learning samples. 
Table 6. Incorrectly predicted learning samples.

\begin{tabular}{ccccccccc}
\hline \multirow{2}{*}{ No. } & \multicolumn{3}{c}{ Expected Output } & \multicolumn{4}{c}{ Actual Output } \\
\cline { 2 - 9 } & IV & III & II & I & IV & III & II & I \\
\hline 2 & 1 & 0 & 0 & 0 & 0 & 0 & 0 & 1 \\
19 & 0 & 1 & 0 & 0 & 0 & 0 & 1 & 0 \\
23 & 0 & 1 & 0 & 0 & 0 & 0 & 0 & 1 \\
36 & 0 & 1 & 0 & 0 & 0 & 0 & 1 & 0 \\
46 & 0 & 0 & 1 & 0 & 0 & 0 & 0 & 1 \\
48 & 0 & 0 & 1 & 0 & 0 & 0 & 0 & 1 \\
52 & 0 & 0 & 1 & 0 & 0 & 0 & 0 & 1 \\
53 & 0 & 0 & 1 & 0 & 0 & 0 & 0 & 1 \\
58 & 0 & 0 & 1 & 0 & 0 & 0 & 0 & 1 \\
66 & 0 & 0 & 0 & 1 & 0 & 0 & 1 & 0 \\
83 & 0 & 0 & 0 & 1 & 0 & 1 & 0 & 0 \\
\hline
\end{tabular}

\section{Conclusions}

The safety and scheduling of hydropower station construction are seriously affected by rockburst disaster, which restricts the sustainable development of hydropower energy. Therefore, a method for rockburst prediction in the deep tunnels of hydropower stations based on the use of real-time MS monitoring information and the MIVA-MFA-PNN model is proposed in this paper. In the proposed MIVA-MFA-PNN model, the MIVA is used to reduce the dimension of the original evaluation index in the PNN, reducing interference from redundant information in the sample as well as the input layer neuron and structural complexity of the PNN. Considering the properties of the smoothing factor in the PNN, three improvements are made in the standard firefly algorithm, and the MFA is proposed to improve global search ability and the rate of convergence. The error caused by empirical determination of the smoothing factor is avoided. Therefore, combining the new model with the real-time monitored MS information obtains good prediction results for rockburst in the tunnels of hydropower projects. The proposed prediction method is verified and analyzed based on 93 rockburst events with different intensities that occurred in parts of the diversion and drainage tunnels of the Jinping II hydropower station, China (with a maximum depth of $2525 \mathrm{~m}$ ). The performance of the MIVA-MFA-PNN model is good.

During the construction of deep tunnels in hydropower stations, the proposed method can be used for risk warning of rockburst. Therefore, rockburst disaster will be reduced and the safety of the construction and sustainable development of hydropower energy will be ensured. However, the mechanism of rockburst formation is complicated in deep tunnels of hydropower stations. Future work will focus on the feasibility of the proposed rockburst prediction model in other deep tunnels of hydropower station projects.

Author Contributions: Investigation, Y.X.; Methodology, G.X.; Project administration, B.C.; Resources, G.F.; Supervision, G.F.; Writing-Original Draft, G.X.; Writing—Review and Editing, G.F. and R.Z.

Funding: This research was funded by the National Natural Science Foundation of China, grant numbers 51709256 and 51621006.

Conflicts of Interest: The authors declare no conflict of interest.

\section{Nomenclatures}

The following terms with symbols and abbreviations are used in this manuscript.

\begin{tabular}{ll}
\hline MS & Microseismic \\
\hline PNN & Probabilistic neural network \\
MIVA & Mean impact value algorithm \\
MFA & Modified firefly algorithm \\
\hline
\end{tabular}




\begin{tabular}{|c|c|}
\hline IV & Impact value \\
\hline$X$ & Input vector of PNN \\
\hline$k$ & Number of neurons \\
\hline$z_{k}$ & $k$ th neuron \\
\hline$w_{k}$ & Weight of $k$ th neuron in the input layer \\
\hline$p$ & Dimension of each sample \\
\hline$\sigma$ & Smoothing factor \\
\hline$m$ & Number of classes to be identified \\
\hline$v_{m}$ & Class output \\
\hline$l$ & lth neuron in the pattern layer \\
\hline$Q$ & Total number of neurons of class $m$ \\
\hline$y$ & Output category \\
\hline MIV & Effect of fluctuations of the parameter on the output of the neural network \\
\hline$i, j$ & Firefly number \\
\hline$n$ & Number of fireflies \\
\hline$x_{i}, x_{j}$ & Positions of firefly $i$ and $j$, or a possible solution to the objective function \\
\hline$I_{i}$ & Absolute brightness of firefly $i$ \\
\hline$I_{i j}$ & Relative brightness of firefly $i$ compared to firefly $j$ \\
\hline$\gamma$ & Light absorption coefficient \\
\hline$r_{i j}$ & Euclidean distance from firefly $i$ to firefly $j$ \\
\hline$\beta_{i j}$ & Attractive force between firefly $i$ and firefly $j$ \\
\hline$\beta_{0}$ & Largest attraction force of fireflies in the light source \\
\hline$t$ & Times of the current iteration \\
\hline$\alpha \varepsilon$ & Random disturbance term \\
\hline$q$ & Number of fireflies \\
\hline MaxGeneration & Maximum number of iterations \\
\hline rand & Random number of uniform distribution on $[0,1]$ \\
\hline$\beta_{\min }$ & Minimum attraction \\
\hline$N$ & Cumulative number of microseismic events \\
\hline$E$ & Cumulative microseismic energy \\
\hline$V$ & Cumulative microseismic apparent volume \\
\hline$n$ & Microseismic event rate \\
\hline$e$ & Microseismic energy rate \\
\hline$v$ & Microseismic apparent volume rate \\
\hline$r$ & Correlation coefficient \\
\hline$x_{a b}$ & Value of microseismic parameter before normalization \\
\hline$x_{a b}^{*}$ & Normalized value of microseismic parameter \\
\hline$x_{\max }$ & Largest value of microseismic parameter \\
\hline$x_{\min }$ & Smallest value of microseismic parameter \\
\hline$P_{N}$ & Microseismic event index \\
\hline$P_{E}$ & Microseismic energy index \\
\hline$P_{V}$ & Microseismic apparent volume index \\
\hline$M I V_{N}$ & MIV of evaluation index $N$ \\
\hline$M I V_{n}$ & MIV of evaluation index $n$ \\
\hline$M I V_{L g E}$ & MIV of evaluation index $L g E$ \\
\hline$M I V_{\text {Lge }}$ & MIV of evaluation index $L g e$ \\
\hline$M I V_{L g V}$ & MIV of evaluation index $\operatorname{LgV}$ \\
\hline$M I V_{L g v}$ & MIV of evaluation index $L g v$ \\
\hline IV & Intense rockburst \\
\hline III & Moderate rockburst \\
\hline II & Slight rockburst \\
\hline I & No rockburst \\
\hline
\end{tabular}




\section{Appendix A Pseudocode for Searching of the Smoothing Factor in the PNN Model}

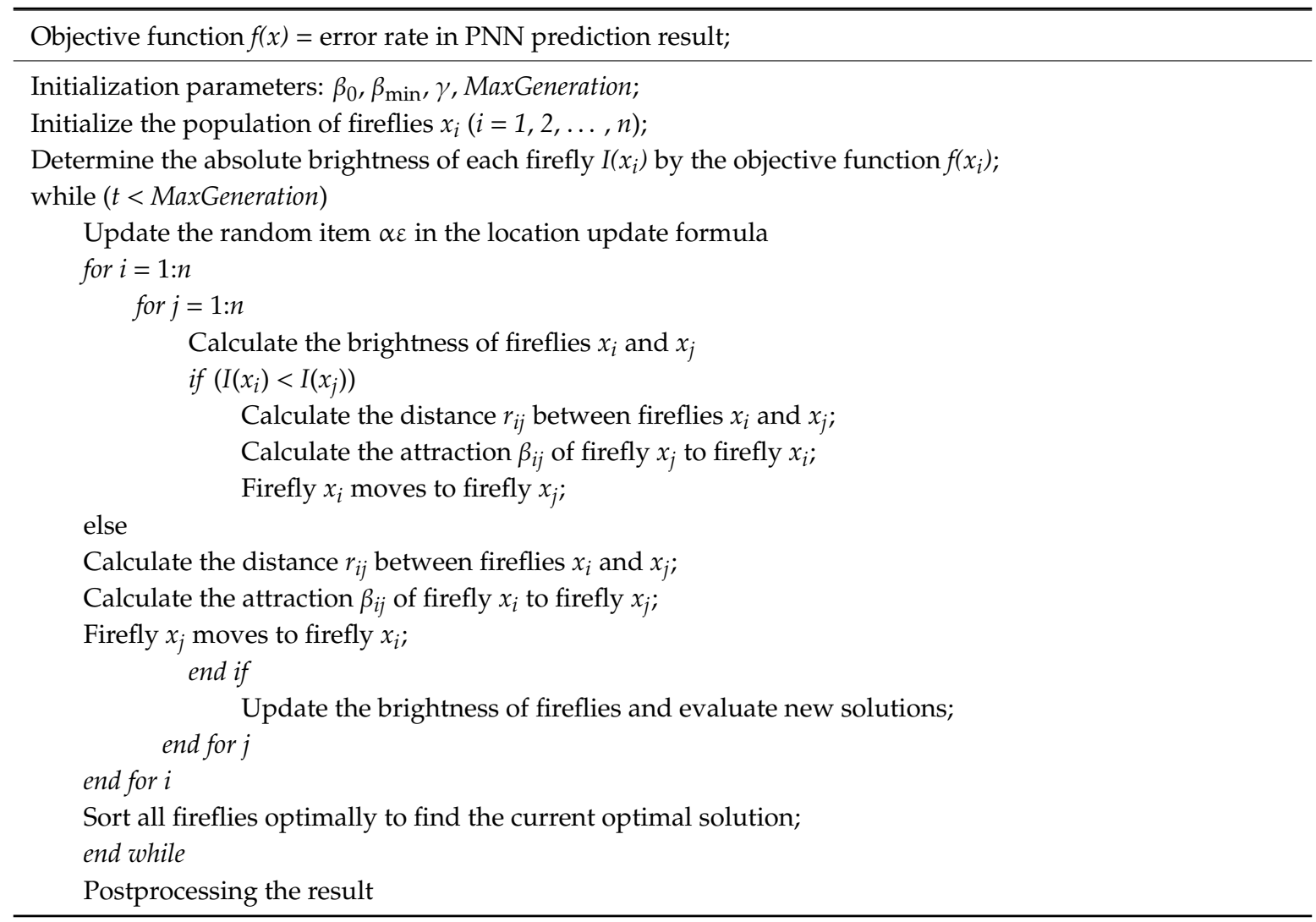

\section{References}

1. Bahtiyor, R.E.; Mona, G.P.S.; Sanaatbek, K.S.; Ruzumboy, A.E. Rogun dam-path to energy independence or security threat? Sustainability 2011, 3, 1573-1592.

2. Tang, W.Y.; Li, Z.M.; Tu, Y. Sustainability risk evaluation for large-scale hydropower projects with hybrid uncertainty. Sustainability 2018, 10, 138. [CrossRef]

3. IRENA. Renewable Energy Statistics 2017; The International Renewable Energy Agency: Abu Dhabi, UAE, 2017; pp. 8-34. ISBN 978-92-9260-0334.

4. Spänhoff, B. Current status and future prospects of hydropower in Saxony (Germany) compared to trends in Germany, the European Union and the World. Renew. Sustain. Energy Rev. 2014, 30, 518-525.

5. Jiang, T.; Shen, Z.Z.; Liu, Y.; Hou, Y.Y. Carbon footprint assessment of four normal size hydropower stations in China. Sustainability 2018, 10, 2018. [CrossRef]

6. Niu, C.C.; Wang, Q.; Chen, J.P.; Zhang, W.; Xu, L.M.; Wang, K. Hazard assessment of debris flows in the reservoir region of Wudongde hydropower station in China. Sustainability 2015, 7, 15099-15118. [CrossRef]

7. Abdul, M.N.; Hafeezur, R.; Muhammad, Z.E.; Hankyu, Y. Impact of shear zone on rockburst in the deep Neelum-Jehlum Hydropower tunnel: A numerical modeling approach. Energies 2018, 11, 1935.

8. Feng, X.T. Rockburst: Mechanism, Monitoring, Warning and Mitigation; Butterworth-Heinemann: Oxford, UK, 2017.

9. Hedleym, D.G.F. Rockburst Handbook for Ontario Hardrock Mines; CANMET Special Report SP92-1E; Energy, Mines and Resources Canada: Toronto, ON, Canada, 1970.

10. Kaiser, P.K.; Tannant, D.D.; McCreath, D.R. Canadian Rockburst Support Handbook; Geomechanics Research Centre, Laurentian University: Sudbury, ON, Canada, 1996.

11. Goran, V.; Maja, K.; Milivoj, V. Study of coal burst source locations in the velenje colliery. Energies 2016, 9, 507.

12. Liu, X.F.; Xu, G.; Zhang, C.; Kong, B.; Qian, J.F.; Zhu, D.; Wei, M.Y. Time effect of water injection on the mechanical properties of coal and its application in rockburst prevention in mining. Energies 2017, 10, 1783. [CrossRef] 
13. Wang, Z.Y.; Dou, L.M.; Wang, G.F. Mechanism analysis of roadway rockbursts induced by dynamic mining loading and its application. Energies 2018, 11, 2313. [CrossRef]

14. Feng, G.L.; Feng, X.T.; Chen, B.R.; Xiao, Y.X.; Yu, Y. A microseismic method for dynamic warning of rockburst development processes in tunnels. Rock Mech. Rock Eng. 2015, 48, 2061-2076. [CrossRef]

15. Feng, G.L.; Feng, X.T.; Chen, B.R.; Xiao, Y.X.; Zhao, Z.N. Effects of structural planes on the microseismicity associated with rockburst development processes in deep tunnels of the Jinping-II hydropower station, China. Tunn Undergr. Space Technol. 2019, 84, 273-280. [CrossRef]

16. Ma, T.H.; Tang, C.A.; Tang, L.X.; Zhang, W.D.; Wang, L. Rockburst characteristics and microseismic monitoring of deep-buried tunnels for Jinping II hydropower station. Tunn Undergr. Space Technol. 2015, 49, 345-368. [CrossRef]

17. Zhang, H.; Chen, L.; Chen, S.G.; Sun, J.C.; Yang, J.S. The spatiotemporal distribution law of microseismic events and rockburst characteristics of the deeply buried tunnel group. Energies 2018, 11, 3257. [CrossRef]

18. Cheng, G.W.; Ma, T.H.; Tang, C.A.; Liu, H.; Wang, S. A zoning model for coal mining-induced strata movement based on microseismic monitoring. Int. J. Rock Mech. Min. Sci. 2017, 94, 123-138. [CrossRef]

19. Feng, G.L.; Feng, X.T.; Chen, B.R.; Xiao, Y.X. Microseismic sequences associated with rockbursts in the tunnels of the Jinping II hydropower station. Int. J. Rock Mech. Min. Sci. 2015, 80, 89-100. [CrossRef]

20. Feng, G.L.; Feng, X.T.; Chen, B.R.; Xiao, Y.X.; Jiang, Q. Sectional velocity model for microseismic source location in tunnels. Tunn Undergr. Space Technol. 2015, 45, 73-83. [CrossRef]

21. Xu, N.W.; Li, T.B.; Dai, F.; Zhang, R.; Tang, C.A.; Tang, L.X. Microseismic monitoring of strainburst activities in deep tunnels at the Jinping II hydropower station, China. Rock Mech. Rock Eng. 2016, 49, 981-1000. [CrossRef]

22. Liu, J.P.; Feng, X.T.; Li, Y.H.; Xu, S.D.; Sheng, Y. Studies on temporal and spatial variation of microseismic activities in a deep metal mine. Int. J. Rock Mech. Min. Sci. 2013, 60, 171-179. [CrossRef]

23. Dai, F.; Li, B.; Xu, N.W.; Fan, Y.L.; Zhang, C.Q. Deformation forecasting and stability analysis of large-scale underground powerhouse caverns from microseismic monitoring. Int. J. Rock Mech. Min. Sci. 2016, 86, 269-281. [CrossRef]

24. Dong, L.J.; Wesseloo, J.; Potvin, Y.; Li, X.B. Discriminant models of blasts and seismic events in mine seismology. Int. J. Rock Mech. Min. Sci. 2016, 86, 282-291. [CrossRef]

25. Li, B.; Li, T.; Xu, N.W.; Dai, F.; Chen, W.F.; Tan, Y.S. Stability assessment of the left bank slope of the Baihetan hydropower station, southwest China. Int. J. Rock Mech. Min. Sci. 2018, 104, 34-44. [CrossRef]

26. Wang, P.; Chang, X.; Zhou, X.Y. Estimation of the relative arrival time of microseismic events based on phase-only correlation. Energies 2018, 11, 2527. [CrossRef]

27. Zhu, Z.; Zhang, H.; Han, J.; Lv, Y.C. A risk assessment method for rockburst based on geodynamic environment. Shock Vib. 2018, 2018, 2586842. [CrossRef]

28. Wang, C.; Chuai, X.; Shi, F.; Gao, S.; Bao, T.C. Experimental investigation of predicting rockburst using Bayesian model. Geomech. Eng. 2018, 15, 1153-1160.

29. Peng, Y.H.; Peng, K.; Zhou, J.; Liu, Z.X. Prediction of classification of rockburst risk based on genetic algorithms with SVM. Appl. Mech. Mater. 2014, 628, 383-389. [CrossRef]

30. Liu, Z.B.; Shao, J.F.; Xu, W.Y.; Meng, Y.D. Prediction of rockburst classification using the technique of cloud models with attribution weight. Nat. Hazards 2013, 68, 549-568. [CrossRef]

31. Tao, H.; Qiao, M. Rockburst prediction based on multivariate time series reconstruction and GRNN. In Proceedings of the 33rd Chinese Control Conference, Nanjing, China, 28-30 July 2014; pp. 5113-5117.

32. Gao, W. Forecasting of rockbursts in deep underground engineering based on abstraction ant colony clustering algorithm. Nat. Hazards 2015, 76, 1625-1649. [CrossRef]

33. Specht, D.F. Probabilistic neural networks. Neural Netw. 1990, 3, 109-118. [CrossRef]

34. Zhou, Y.; Wang, T. PNN-based rockburst prediction model and its applications. Earth. Sci. Res. J. 2017, 21, 141-146. [CrossRef]

35. Kowalski, P.A.; Kusy, M. Sensitivity analysis for probabilistic neural network structure reduction. IEEE Trans. Neural Netw. Learn. Syst. 2018, 29, 1919-1932. [CrossRef]

36. Kusy, M.; Zajdel, R. Application of reinforcement learning algorithms for the adaptive computation of the smoothing parameter for probabilistic neural network. IEEE Trans. Neural Netw. Learn. Syst. 2015, 26, 2163-2175. [CrossRef] [PubMed]

37. Duda, R.O.; Hart, P.E.; Stork, D.G. Pattern Classification, 2nd ed.; Wiley: Hoboken, NJ, USA, 2004. 
38. Dombi, G.W.; Nandi, P.; Saxe, J.M.; Ledgerwood, A.M.; Lucas, C.E. Prediction of rib fracture injury outcome by an artificial neural networks. J. Trauma Acute Care Surg. 1995, 39, 915-921. [CrossRef]

39. Yang, X.S. Nature-Inspired Metaheuristic Algorithms; Luniver Press: Frome, UK, 2008.

40. Theofanis, T.; Aristidis, V. Application of the firefly algorithm for solving the economic emissions load dipatch problem. Int. J. Comb. 2011, 26, 93-96.

41. Yu, S.; Su, S.; Lu, Q.; Huang, L. A novel wise step strategy for firefly algorithm. Int. J. Comput. Math. 2014, 91, 2507-2513. [CrossRef]

42. Pearson, k. Notes on regression and inheritance in the case of two parents. Proc. R. Soc. Lond. 1895, 58, 240-242.

(C) 2019 by the authors. Licensee MDPI, Basel, Switzerland. This article is an open access article distributed under the terms and conditions of the Creative Commons Attribution (CC BY) license (http://creativecommons.org/licenses/by/4.0/). 